\title{
The Role of Enterprise Social Media in the Development of Aerospace Industry Best Practices
}

\author{
Nancy Doumit ${ }^{1}$, Greg Huet ${ }^{2}$, and Clément Fortin ${ }^{1}$ \\ ${ }^{1}$ Department of Mechanical Engineering, École Polytechnique of Montreal, Canada \\ \{nancy.doumit, clement.fortin\} @polymtl.ca \\ ${ }^{2}$ Department of Automated Production Engineering, École de Technologie Supérieure, \\ Montreal, Canada \\ Gregory.Huet@etsmtl.ca
}

\begin{abstract}
This paper presents a new approach for the development of best practices in the aerospace industry through social media. A survey and semistructured interviews used on a smaller sample suggest that integrating social media to formal organizational structures around a community of practice could indeed be employed to facilitate knowledge and experience sharing between established experts and participants. Finally, this paper also explores the extension of this framework to complement more formal and structured information processes typically managed by PLM solutions to better support the development of best practices via communities of practice. In this case, a complementary link between best practices under development in a community of practice and the design solution being developed in the Digital Mock-Up is presented.
\end{abstract}

\section{Introduction}

Best practices as clarified by Szulanski (1996) are a "replication of an internal practice that is performed in a superior way to internal alternated practices and known alternatives outside the company. The practice refers to the organization routine use of knowledge and often has tacit component embedded". The widespread terminology of "best" practice however can easily lead to confusion; it is not so much a universal practice, but rather a localized one related to a specific context. Methodologies and tools in engineering are typically based on a set of theoretical foundations but many are then adapted in their practical formulation in order to meet the specific needs of their implementation context. A common illustration of this would be the use of the House of Quality methodology in different companies. Although the general framework does not vary, each firm will adapt the tool to suit the specific objectives of its implementation. These "in house" adaptations or variants are typically documented in the form of best practices (Cristiano et al. 2000). In order to generate and validate this type of corporate knowledge, companies rely on experienced users to rationalize, document, and disseminate best practices using a network of colleagues and following a standard verification and validation process. Although best practices 
are quite obviously a core item of corporate knowledge, their production is time consuming and their use across projects and departments can be erratic. This research targets improved approaches to best practice development in aerospace, more specifically the study explores how enterprise social media could be used to improve best practice sharing within a community of practice. The data is based on an industrial case study from which qualitative aspects have been analyzed. The observations and conclusions reported in the paper are grounded on information gathered from interviews and process maps. Before presenting the results of the case study, the current role and perceived value of social media in the enterprise is reviewed.

\section{Social Media in the Enterprise}

In the context of the enterprise and from a systems perspective, social media poses interesting challenges. Indeed, enterprise social networking activities through internet based social software suggest a number of different scenarios that in some cases involve radical transformations with respect to the borders of the enterprise system and its environment. To some extent, many of these "new" collaboration scenarios have always existed but through informal and often secretive mechanisms; the support offered by social software and the internet has quite simply extended communication modes and collaborative knowledge sources that could not have been imagined even a decade ago.

Should social media be bounded by the borders of the enterprise? Wouldn't this limit the collaborative knowledge potential that social networking brings to the table? Are some departments or teams at risk of jeopardizing their decisional influence with respect to operational processes?

As these question suggest, most of the concerns related to the deployment of social software in the enterprise are related to information security and quality; the communication and collaboration potential of this new medium characterized by its informal and spontaneous attributes is counterbalanced by a risk of Intellectual Property leakage. Moreover, policies in place imply that all information shared, whether it is be through formal or informal communication processes, is subjected to governmental aviation authority regulations (EASA, FAA, etc.). From a judicial perspective, social media are considered an extension of electronically stored information -ESI- (Carlisle 2012) and the same tracking rules apply to any information/document shared on this kind of platform. Businesses are therefore obliged to develop guidelines, policies and procedures to safeguard from legal action. In this paper, the integration of social computing in the enterprise is viewed in a context which avoids these organizational dilemmas. The role of enterprise social media in the development of aerospace industry best practices is studied in a specific environment where the networking activities take place within the boundaries of a firm. 


\subsection{Use of Social Media to Support Communities of Practice}

Over the last two decades, a new recognized group structure - Communities of Practice - has emerged to complement the existing formal work breakdown structures that divide a company, e.g. departments, functions or Integrated Product Teams. According to Wenger and Sydner (2000) Communities of Practice (CoP) can be defined as "groups of people informally bound together by shared expertise and passion for a joint enterprise". A CoP is therefore characterized by a domain, a group of people (the community), and shared practices. The domain is typically an expertise that is practiced by a number of individuals engaged in sharing the knowledge and experiences through joint activities and discussions. In an enterprise context, CoPs are consolidated through five means: mutual engagement, interpersonal relationships, joint enterprise, identity acquisition and shared repertory (Wenger 1999).

With the various collaborative features proposed by social software, technology now plays an important role in the establishment and vitality of CoPs. They enable the virtual exchange of information between collocated and distributed communities, also known as Virtual Communities of Practice, i.e. "CoPs supported by information and communication technologies" (Annabi et al. 2012).

Social media rely on a number of collective participation tools such as blogs (individual authorship) or wikis (group authorship) to capture and distribute information. McAfee (2006) proposes an interesting classification of the types of activities that can be supported by social software in the context of the enterprise under the acronym "SLATES" (Search, Links, Authoring, Tags, Extensions and Signals).

\section{Improving Best Practices through Social Media}

The field study on best practices carried out by the authors encompasses two specific investigations: a study of the company's current processes and semi structured interviews. Results from these two investigations are reported in this paper. It is important to note that the notions of "best practices" in this study are essentially related to the following types of contents:

- Design aspects that needed to be taken into consideration during the preliminary design phase. ( e.g.: Maintenance and accessibility criteria)

- The types of analysis required. (e.g.: Pressure drop analysis)

- Design evaluation criteria and preferred tool to meet those criteria. (e.g.: Nominal clearance between systems)

- $\quad$ Procedures specific to the department under study. (e.g.: Parts release)

\subsection{Process Based Analysis}

In this section, the descriptive study of a best practice development process aims at providing the reader with an illustrated reference of the actual approach taken by the company without the use of a social media. The data used to build the best practice development process presented in Fig. 1 was based on existing documentation and a work session with various experts in the department to validate the map. 


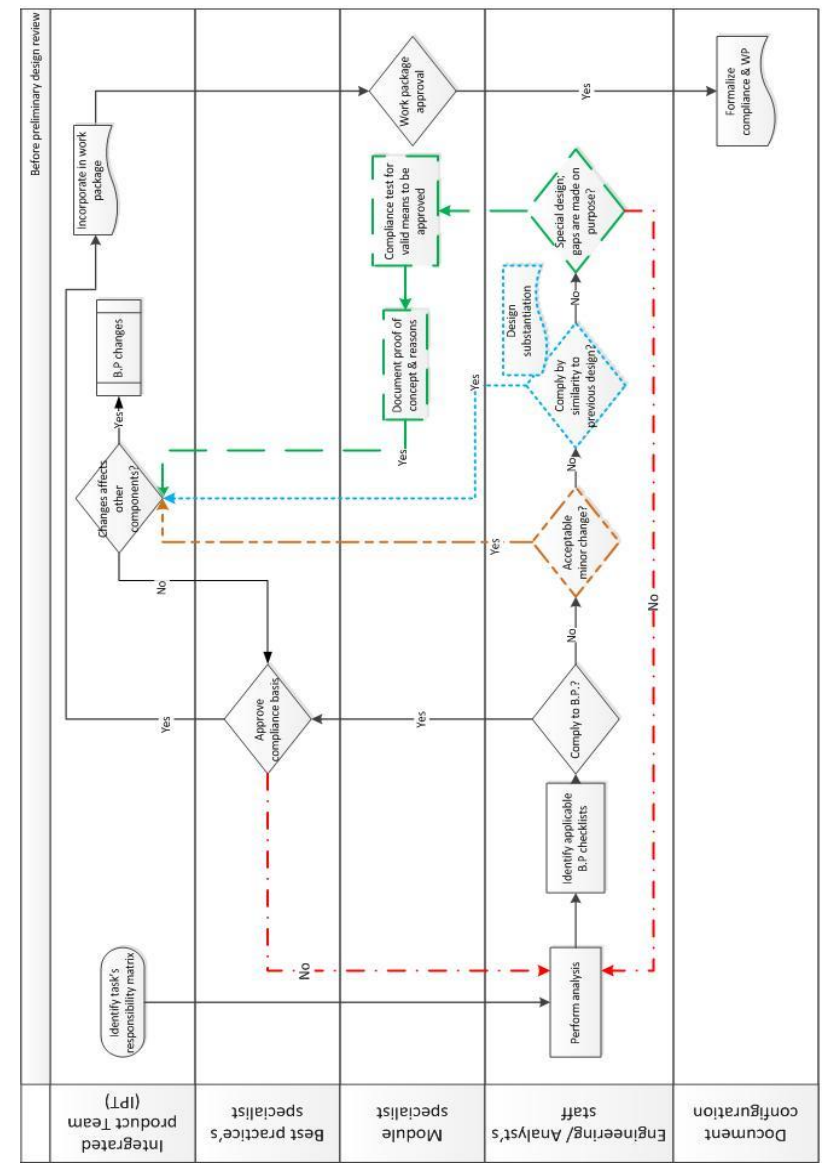

Fig. 1. Best practice development process in an aerospace company

The process highlights a long validation process of the best practice's check list. It is very sequential and activities are therefore executed through a linear flow path up to the validation gate. It is important to note that information is not shared among the different roles for feedback unless the designer has collected a minimum required set of proof of compliance. This is a rather inefficient approach as external parties have generally more objectivity to identify missing information. Furthermore the close supervision of an expert would help point to similarities in previous designs. The information is only shared late in the process hence exposing the best practice development to greater rework. 


\subsection{Interview Analysis}

The preliminary process analysis was used to build a semi structured interview focusing on current best practice development process in the company. An initial list of participants was suggested by the company. Most engineers who were interviewed also recommended colleagues to interview or referred to another department or discipline. In this study the authors only reported interviews that were conducted in one specific department. Semi structured interviews were conducted with ten engineers with different degrees of seniority working in the same department but sometimes on different projects. The results presented in this paper have been summarized according to four research questions.

\section{Question 1: When do you refer to best practices to validate your design activities?}

The experienced engineers suggested that they had a working knowledge of the best practices and therefore hardly ever consult the documents. New employees ( 2 years of experience or less) are not always aware of the existence of a best practice for a given design task and for them finding any kind of useful information and guidance is already a challenge in itself. This case highlighted a basic yet important requirement for best practice distribution: when a design task is initiated, the users must have a reminder of the corresponding company best practices.

Question 2: What happens when a given design task ignores an existing best practice?

If the design does not follow the best practice's guideline, five typical cases were raised by the participants and have been summarized in table 1 .

Table 1. Discrepancy scenarios between a design tasks and its corresponding best practice

\begin{tabular}{ll}
\hline Discrepancy & Typical mitigation \\
$\begin{array}{l}\text { Case 1: The process or } \\
\text { methodology used is similar to the } \\
\text { best practice }\end{array}$ & $\begin{array}{l}\text { The designer must detail a "proof of similarity" with previous } \\
\text { designs. The proof is verified by best practice specialists before } \\
\text { approval }\end{array}$ \\
$\begin{array}{ll}\text { Case 2: The results do not affect } \\
\text { safety and do not impact other } \\
\text { components. }\end{array}$ & $\begin{array}{l}\text { The designer must flag the component so that this result cannot } \\
\text { be used as a proof of similarity on future designs }\end{array}$ \\
$\begin{array}{ll}\text { Case 3: The divergence with the } \\
\text { best practice has been endorsed by }\end{array}$ & $\begin{array}{l}\text { A request for approval from the best practices specialist must be } \\
\text { sought. A revision of the corresponding process based best } \\
\text { the IPT }\end{array}$ \\
$\begin{array}{ll}\text { Case } 4: \text { A request for change of } \\
\text { best practice is required }\end{array}$ & $\begin{array}{l}\text { The formal change management process is engaged very much } \\
\text { like a design change on a released part. Many different actors are }\end{array}$ \\
involved in this prolonged amendment process. \\
Case 5: All cases above are & $\begin{array}{l}\text { The design must be entirely revised to meet best practice } \\
\text { requirements }\end{array}$ \\
rejected
\end{tabular}


Question 3: What would be your suggestions in terms of tools to improve best practice dissemination?

"Message boards with very specific topics. Currently we write memos to summarize the knowledge but they are not generally categorized. Organizing them into a coherent structure would certainly help in finding relevant data.".

"Efficient search engine and better indexing, the ability to write and properly control non-technical data is what we need".

A forum under a question/answer format could ease the clarification of a specific requirement or interpretation of an analysis. Since several companies have already their internal wikis, the majority of interviewees agreed on adding a wiki platform to share definitions and know how; "currently, only one person can work on a document at any one time. The only way around this is to use shared worksheets on public drives" more specifically some asked for "wiki pages". People expressed also their need to have a list of people outside the team with their expertise to know who they must contact.

The scope of the interview was wider than just best practice development and aimed at measuring the interest of using social media around a community of practice to facilitate knowledge and experience sharing between established employees. Fourteen engineers answered the questions.

Of all the respondents, only one had heard about an existing community of practice in another department. A short review on CoPs was therefore programmed as a training activity for the department._For the purpose of this study, only the results concerning the features of social software are presented. Figure 2 summarizes the results for each category of feature.

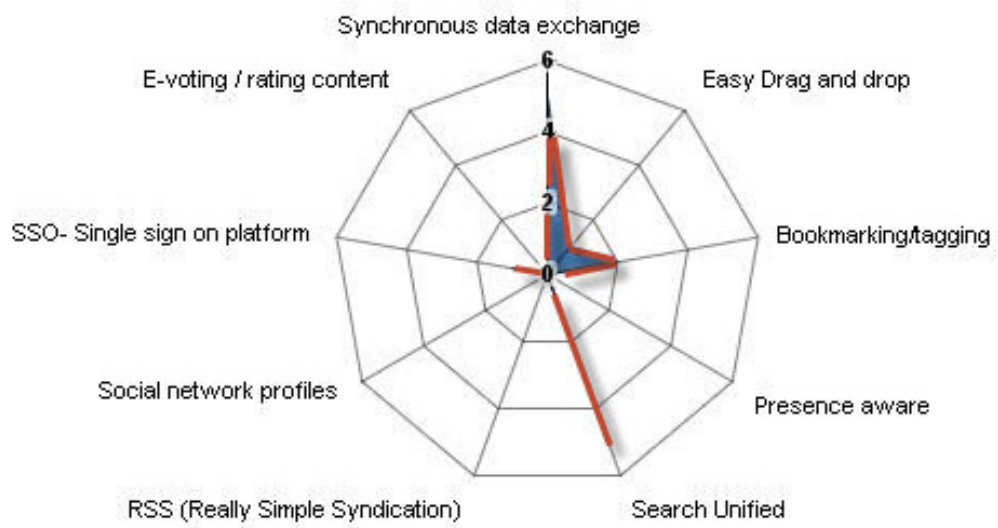

Fig. 2. Social media features relevant to engineering day to day work

This analysis confirmed what had been said during the interviews. Indeed, users need to edit documents at the same time while having a unified search $(36 \%)$. Engineers first want to solve their current barriers in information sharing; once a single platform (7\%) answers their needs in term of co-authoring (36\%) and tagging (14\%) they might need extra features to enhance the collaboration process. 


\subsection{Future State: Developing Best Practices Using Social Media}

In this prescribed scenario, engineers can openly join any engineering community or can be requested to join one for the purpose of a specific project. The community exists as long as the design is not in production or there is interest to keep it (indicating the existence of a key knowledge domain).

As a first interaction, designers would make use of the "discussion" type features such as a question/answer (Q/A) forum to get insight about the job to do. As shown in Figure 3, the essential contribution of the design focused virtual community of practice is to facilitate the problem definition phase, i.e. when designers make hypotheses and look for constraints related to the perceived tasks (typically found in company best practices). Thanks to the virtual CoP, knowledge is gradually and collaboratively explored with the inputs from at least the following key participants: moderator, best practice specialist, subject expert, security/legal representative.

Based on the investigations reported in the previous sections of this paper, the authors prescribed a preliminary best practice development process integrating social media. A generic version of this process is illustrated in figure 3.

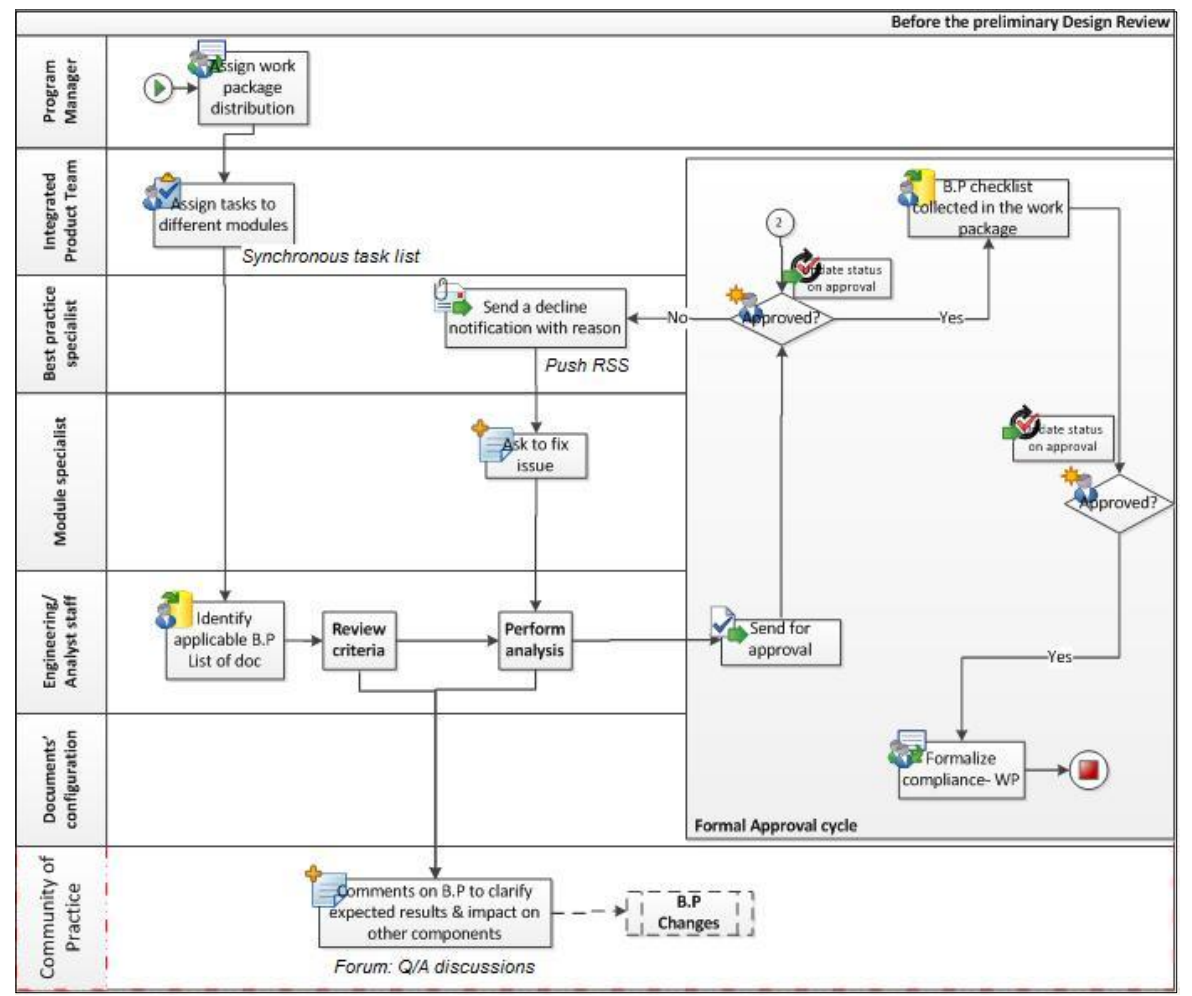

Fig. 3. Prescribed best practice development 


\section{The Potential Role of PLM and Future State}

With the advent of Social PLM (Brown 2012), the aforementioned benefits of social software could be integrated to a more secure information platform used by a number of engineering designers. Hence, information about a product and the related know how could be exchanged in a continuous workflow and once formalized would then be pushed to a single secure location in the PLM. Distributed information on social media would follow a maturity curve up to a certain level of confidence where the information is formalized and attached to the controlled product structure. Social tools could be extended to support some formal data as the maturity of the data evolves.

Since the focus of ongoing research is on the best practice definition and refinement, a correlation with the above proposition can be made with the current study: knowledge about a specific component could be shared among CoPs based on the best practices as knowledge references, then formalized and linked to the product structure as it reaches a certain maturity level.

For the aerospace case study, this framework can be achieved using two different approaches: either two separate platforms (PLM and Social Media) or imbedded social functionalities within the PLM software. In the case where both platforms a separated, the social networking advantages are made available to the entire company and focused on knowledge sharing at large; indeed, PLM remains more of a specialist tool and as such does not propose the same user friendliness nor does it really extend to the entire enterprise (Huet et al. 2012). On the other hand, imbedded social features propose a unified platform to engineers. Both approaches need nonetheless to be pursued as social media is now well documented to offer the unique advantage of converting collaborative tacit knowledge into explicit information (Panahi et al. 2012).

Even though using social media to support virtual CoPs has been successfully demonstrated (Michaelides et al. 2010), there are few reported studies on the use of virtual CoPs to share engineering design knowledge. Further work needs to be done to ensure the validity of the proposition and as such this paper should be regarded as a work in progress. The research is now set to focus on establishing the detailed requirements for the customization of enterprise social software in the company with the constraints of complementing the use of a large PLM platform.

\section{References}

Annabi, H., McGann, S.T., Pels, S., Arnold, P., Rivinus, C.: Guidelines to align communities of practice with business objectives: An application of social media. In: 45th Hawaii International Conference on System Sciences (HICSS), Maui, Hawaii, pp. 3869-3878. IEEE (January 2012)

Brown, J.: Social Business Collaboration and the Product Lifecycle: Combining the Collaborative Power of Social Media with PLM. Tech-Clarity, Inc., http: / / www . techclarity.com/documents/Tech-Clarity_IssueinFocus_Social_ Business_PLM.pdf (accessed January 1, 2012) 
Carlisle, D.: Legal issues for business use of social media. Available via ARMA International, http: / /www .arma.org/r1/news / newswire/2012/06/27/legal-issuesfor-business-use-of-social-media (accessed November 12, 2012)

Cristiano, J.J., Liker, J.K., White, C.C.: Customer-driven product development through quallity function deployment in the U.S and Japan, vol. 17, pp. 286-308 (2000)

Giles, J.: Internet encyclopaedias go head to head. Nature 438(7070), 900-901 (2005), doi: $10.1038 / 438900 a$

Hoffmann, E.: Defining information: An analysis of the information content of documents. Information Processing \& Management 16(6), 291-304 (1982), doi:10.1016/S03064573(80)80011-2

Huet, G., Zeng, Y., Fortin, C.: Theoretical foundations supporting the implementation of complementary information structures across the life of a product. In: ASME 2012 11th Biennial Conference on Engineering Systems Design and Analysis, Nantes, France, July 2 (2012)

Kaplan, A.M., Haenlein, M.: Users of the world, unite! The challenges and opportunities of Social Media. Business Horizon 53(1), 59-68 (2010), doi:10.1016/j.bushor.2009.09.003

Young, M.J., Salerno, J., Liu, H.: Social computing and behavioral modeling. Springer, US (2009), doi:10.1007/978-1-4419-0056-2

McAfee, A.: Enterprise 2.0: The dawn of emergent collaboration. IEEE Engineering Management Review 34(3), 38 (2006), doi:10.1109/EMR.2006.261380

Michaelides, R., Tickle, M., Morton, S.: Online communities of practice for innovation and knowledge transfer: A case study in the UK. In: The 6th IEEE International Conference on Management of Innovation and Technology (ICMIT), Singapore, June 2-5, pp. 922-927 (2010), doi:10.1109/ICMIT.2010.5492861

Panahi, S., Watson, J., Partridge, H.: Social Media and Tacit Knowledge Sharing: Developing a Conceptual Model. In: World Academy of Science, Engineering and Technology (WASET), Paris, France, pp. 1095-1102 (2012)

Schuler, D.: Communications of the ACM 37(1) (1994), doi:10.1145/175222.175223

Szulanski, G.: Exploring internal stickiness: Impediments to the transfer of best practice within the firm. Strategic Management Journal 17(Winter special issue), 27-43 (1996) (1986-1998)

Wenger, E.C.: Communities of practice: Learning, meaning and identity. Cambridge University Press, Cambridge (1999)

Wenger, E.C., Sydner, W.M.: Communities of practice: The organizational frontier. Havard Business Review 78(1), 139-146 (2000)

Wenger, E.C., White, N., Smith, J.D.: Digital habitats: Stewarding technology for communities. CPsquare, Portland (2010) 